\title{
MEDEAS-World Model Calibration for the Study of the Energy Transition
}

\author{
GIANLUCA MARTELLONI ${ }^{1}$
}

gianluca.martelloni@unifi.it

INSTM clo Department of Chemistry, University of Florence (Italy)

ILARIA PERISSI

ilaria.perissi@unifi.it

INSTM clo Department of Chemistry, University of Florence (Italy)

\author{
SARA FALSINI \\ sara.falsini@unifi.it \\ INSTM clo Department of Chemistry, University of Florence (Italy)
}

FRANCESCA Di PATTI

f.dipatti@gmail.com

Consiglio Nazionale delle Ricerche, Institute for Complex Systems

\author{
UGO BARDI \\ ugo.bardi@unifi.it \\ INSTM clo Department of Chemistry, University of Florence (Italy)
}

\begin{abstract}
MEDEAS (Modelling the Energy Development under Environmental And Socioeconomic constraint) World is a new global-aggregated energy-economy-environmental model, which runs from 1995 to 2050. In this work, the MEDEAS world model is tested in order to reproduce the IPCC (International Panel on Climate Change) GHG (Green House Gases) emission pathways consistent with $2{ }^{\circ} \mathrm{C}$ Global Warming. A parameter optimisation of the MEDEAS model, related to different scenarios until 2050, is achieved. Moreover, a sensitivity analysis on the parameters that directly influence the emission curves focusing on the annual growth of the RES (Renewable Energy Sources), GDP (Gross Domestic Product) and annual population growth, is provided. From such an analysis, it has been possible to infer the large impact of GDP on the emission scenarios.
\end{abstract}

${ }^{1}$ Corresponding author. 


\section{Introduction}

MEDEAS World is a global, one region-aggregated economy-energy-environment model which has been developed applying System Dynamics to integrate the knowledge from different perspectives as well as the feedbacks from different subsystems. According to the previous definition, MEDEAS can be classified within the Integrated Assessment Models (IAMs) group of mathematical models, used to explore alternative social, economic, environmental, climatic scenarios and policies (Rotmans et al., 2001; Pfenninger et al., 2017) under a holistic view. However, System Dynamics modelling approach makes MEDEAS able to overcome the traditional IAMs sequential structure that allows only for a restricted number of feedbacks among the represented subsystems. Indeed, it is recognised that IAMs underrepresent the dynamic of the economic dimension, using aggregated production functions and using prices as indicators of scarcity (Scriesciu et al., 2013). Moreover, renewable energy sources (RES) are assumed with no limitations and, most relevant, IAMs often omit climate change assessment and impacts (Dietz et al., 2015; Diaz et al., 2017; Ringkjøb et al., 2017). MEDEAS novel approach proposes a new modelling framework, integrating global biophysical and socioeconomic constraints, providing advanced overtures in interpreting experimental data and in developing more performant IAMs (Capellan-Perez et al., 2019a, 2019b; Solé et al., 2019).

In the present work, an optimisation procedure is developed in order to fit with MEDEAS model the GHG emission scenarios provided by IPCC and integrated by INSTM (Perissi et al., 2018) according to Global Warming $2{ }^{\circ} \mathrm{C}$ consistent. Models' optimisation or identification are common mathematical techniques to calculate the parameters of a dynamical system in order to fit experimental data that represent a physical phenomenon with its model representation. In literature, several examples can be found, in mechanics, engineering, economics and finance, geophysics, biology, ecology, and so on (Dorfman, 1969; Marsili-Libelli, 1992; Martelloni et al., 2013; Santarlasci et al., 2014). Here, the aim is to explore the capability of the model in reproducing 'experimental data' (IPCC and INSTM emissions scenarios), optimising the MEDEAS model's parameters in order to have some indications on how do not exceed the global warming of $2{ }^{\circ} \mathrm{C}$ in practice. In literature, some applications of using IPCC scenarios for calibration model purposes, are present (see Wigley and Raper, 1992; Meinshausen, 2011) but they do not include System Dynamics models. Therefore, our work represents a novelty in the field of System Dynamics. Moreover, the best parameters obtained in reproducing emissions scenarios design an alternative theoretical MEDEAS scenario (Solé et al., 2018) focused on the achievement of the decarbonisation at a global level. For example, it can be assessed how renewable resources should increase in the future, and if the decarbonisation is reached in practice relying only on the current technologies. To this purpose, the assessment of the limits and vulnerabilities of the transition to renewable energy is very important (see Capellán-Pérez et al., 2017a).

The proposed optimisation procedure configures as a general method applicable also for the European and country version of the MEDEAS models and, ultimately, for any integrated assessment model (IAMs) or in system dynamics-based models, where the attribution of some parameters' values are uncertain in reproducing experimental data or scenarios. 


\section{Materials and method}

\subsection{The model}

MEDEAS World model is a global, one region-aggregated economy-energy-environment model which has been developed applying System Dynamics to integrate the knowledge from different perspectives as the feedbacks from different subsystems. MEDEAS world consists of a modular and flexible structure that can be expanded/simplified/replaced by another version or sub-model. MEDEAS model runs from 1995 to 2050 in order to predict the energy transition Fossil Fuels/RES, and it is structured into 7 submodules (Capellán-Pérez et al., 2017b):

1) Economy: It is modelled following a post-Keynesian approach assuming disequilibrium (i.e., non-clearing markets), demand-led growth and supply constraints, integrating the Input-Output Analysis of 35 industrial sectors and households.

2) Energy: This module includes renewable and non-renewable energy resources potentials and availability considering biophysical and temporal constraints. In total, 5 final fuels are considered (i.e., electricity, heat, solids, gases and liquids) and a diversity of energy technologies are modelled, following a net energy approach.

3) Infrastructures: Energy infrastructures represent the power plants to generate electricity and heat.

4) Materials: Materials are required by the economy and MEDEAS tracks the material requirements for the construction and the Operations and Maintenance of the infrastructures.

5) Land Use: It mainly accounts for the land requirements of the RES.

6) Climate Change: This module projects the climate change levels due to the GHG emissions generated by human societies, which also feed-back through a damage function.

7) Social and Environmental Impacts Indicators: this module translates the 'biophysical' results of the simulations into metrics related to social and environmental impacts. The objective is to contextualise the implications for human societies in terms of well-being.

The modules of economy and energy are the most extensive and reach the highest degree of disaggregation. The modules have bi-directional linkages, excepting for the Land-use and Social and Environmental impacts indicators, which mainly report outputs from the simulations without feed-backing to rest of the structure (see Figure 2.1.1).

In terms of general logic, MEDEAS model configures mainly with the purpose to simulate and analyse scenarios based on the user's choices and hypothesis, a powerful tool to support decisions; nevertheless, in the present work, it is shown that MEDEAS model has also all the right credentials to be used as optimisation model with the capability to interpret real data, out of the users' scenarios design. In this sense, the MEDEAS model can be considered a new 'hybrid' model able to combine both simulation and optimisation methodologies. 


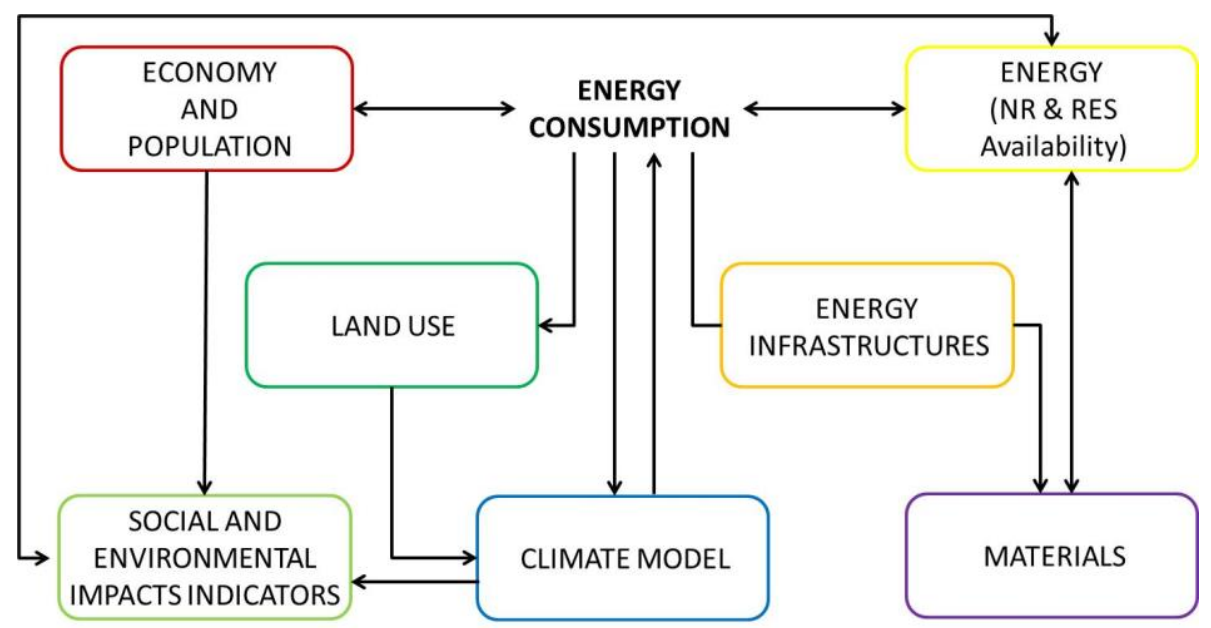

Figure 2.1.1. Overview of MEDEAS-World by modules and the linkages between them. ${ }^{2}$

\subsection{The calibration procedure}

The Optimisation methodology is implemented in MATLAB ${ }^{\circledR}$, which allows running the Python platform in which MEDEAS is developed.

In the block diagram of Figure 2.2.1, the optimisation procedure is schematically described. The calibration algorithm starts using, as initialisation, an excel file containing all parameters that defining a fixed scenario and it works only on the parameters involved in the optimisation (other parameters are constant). Then, the procedure evaluates the error function defined in equation 1 at each time step, varying the values of the parameters and according to the stop criterion, that is, a fixed threshold on the error function and/or a maximum number of iterations. The algorithm goes using its rules (Cardoso, 1996) until the stop criterion is satisfied in order to search the optimised parameters.

\footnotetext{
${ }^{2}$ Available online at https://medeas.eu/model/medeas-model (last accessed: April 15, 2019).
} 


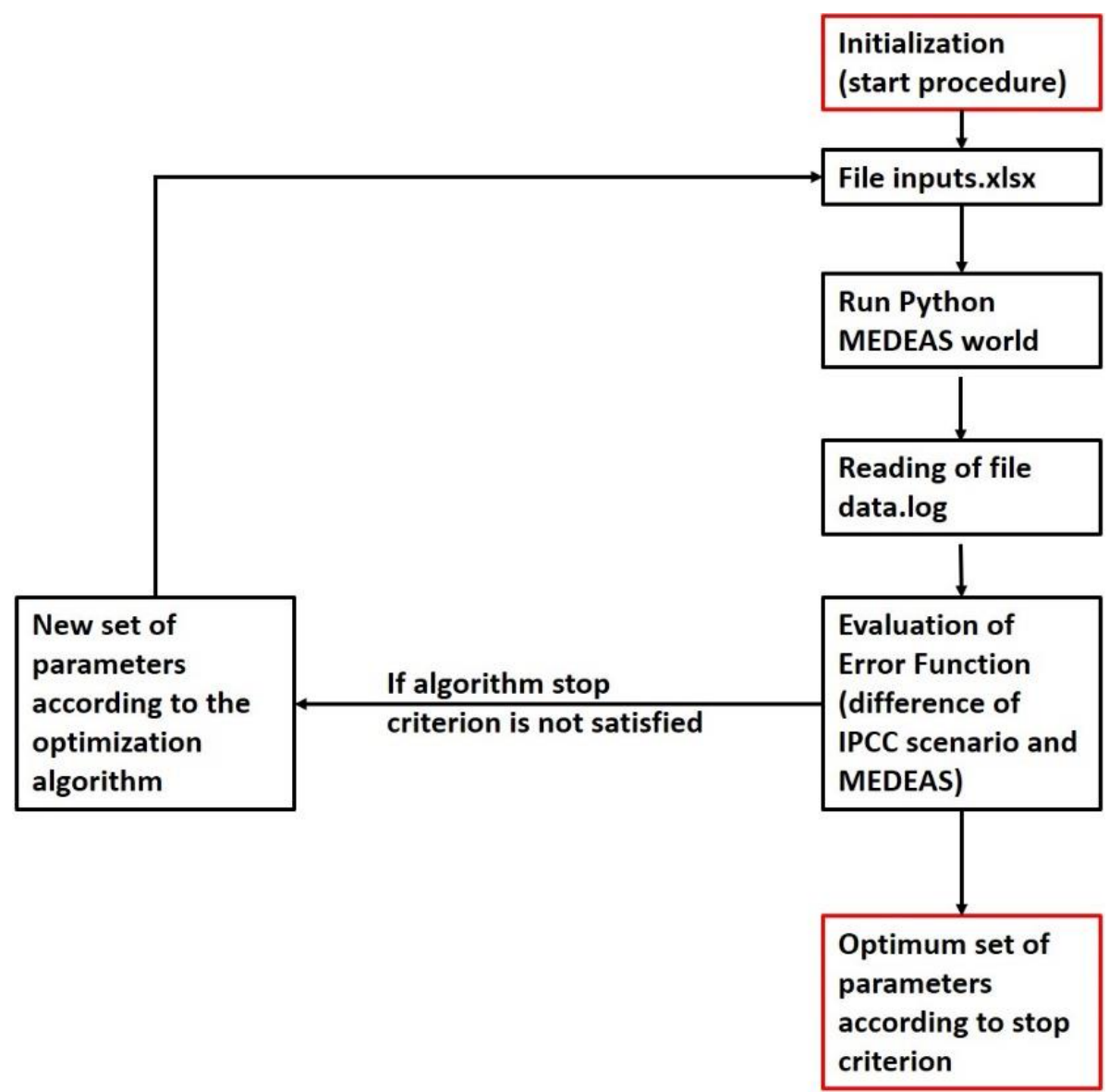

Figure 2.2.1. Block diagram exploiting the optimisation procedure.

Here the results of the optimisation procedure, obtained using SIMPSA algorithm (Cardoso, 1996), is reported to fit the IPCC emission scenario at world level with starting policy from the year 2020 in order to reduce GHG emissions (increment of RES and reduction of fossil fuels). This optimisation algorithm finds the best set of parameters $P=[k 1, \ldots, k i, \ldots, k n]$ which minimise the error function $F(P)$,

$$
\mathrm{F}(\mathbf{P})=\frac{1}{\mathrm{~N}} \sum_{\mathrm{i}=1}^{\mathrm{N}}\left(\mathrm{x}_{\mathrm{i}}^{\mathrm{exp}}-\mathrm{x}_{\mathrm{i}}^{\bmod }(\mathbf{P})\right)^{2}
$$

where $x^{e x p}$ and $x^{\text {mod }}$ indicate respectively the 'experimental' (IPCC/INSTM scenario) and the values obtained with the MEDEAS model on time ( $i$ represents the number of data relative to time in years).

MEDEAS model is extremely complex as it contained many parameters and variables (ca. $4,000)$, so the strategy has been to focus on the calibration of the parameters that directly influenced the emissions: annual growth of RES parameters, the rates of coal and oil extraction, GDP pro capite (GDPpc), and annual population growth (see Results section). These parameters are adjusted starting from Business As Usual (BAU) scenario, which represents the Baseline scenario. In the BAU scenario, no new policies or measures to reduce GHG emissions have been implemented, apart from those currently adopted. Therefore, varying the parameters in Table 3.1, several new scenarios, which differed from the BAU in term of emission pathways, 
can be obtained. In this analysis, it is central to set the search ranges in which the parameters vary, in order to obtain from calibration a set with physical sense. For a complete description of the MEDEAS parameters, see Capellán-Pérez et al. (2017b).

\section{Results}

Firstly, the MEDEAS model is tested in reproducing the IPCC/INSTM decarbonisation scenario (see the red curve in Figure 3.2). In this calibration 39 parameters, 3 for GDPpc, 2 for the population growth and 34 other ones as indicated in Table 3.1 are considered. In the latter, the obtained best parameters and the related ranges, in which the calibration procedure works, are specified. For GDPpc, three parameters and, therefore, three ranges are fixed in order to optimise: the GDPpc initialisation values are respectively $0.06,0.01$ and -0.015 and the ranges are [0.02 0.065] from 2015 to 2020, [0.005 0.015] from 2021 to 2025 and [-0.025 -0.001] from 2026 to 2050. By calibration for the GDPpc, the values $0.0612,0.01$ and -0.0149 are obtained. This choice is based on the hypothesis that GDPpc keeps constant for a certain period but, decreased in a long one consequently to lower consumption, with the aim to reach the ' $2{ }^{\circ} \mathrm{C}$ consistent scenario'. While for the annual population growth a linear function is used: the slope is imposed to vary from -0.00041 to -0.00039 and the intercept from 0.8 to 0.82 ; the initialisation values are respectively -0.0004 and 0.8098 and the obtained best values are respectively -0.00039986 and 0.80986879 . That means the annual population growth decrease until 2025 keeping positive, but it becomes negative after 2025. Noting that the choice of the initialisation values is due to the simple reasons for approaching the reference red curve reported in Figure 3.2, that is, the IPCC/INSTM scenario (red line). This curve has been elaborated considering the global remaining carbon budget estimation in the Climate Action Tracker (CAT) ' $2{ }^{\circ} \mathrm{C}$ consistent scenario', which concerns warming below $2{ }^{\circ} \mathrm{C}$ with at least a $66 \%$ probability over the whole $21^{\text {st }}$ century. The red curve follows the trend from IPCC AR5 scenarios (from Working Group III) from 2012 up to 2020; then, it declines to assure the same carbon budget of $1494 \mathrm{GtCO} 2 \mathrm{eq}$ delimited by the $2^{\circ} \mathrm{C}$ consistent scenario. AR 5 scenario considers, in the absence of policies global warming, to reach $4.1{ }^{\circ} \mathrm{C}-4.8^{\circ} \mathrm{C}$ above preindustrial by the end of the century (higher and lower trend assessments with no policy, black lines Figure 3.2) with a carbon budget much higher than the $2^{\circ} \mathrm{C}$ median considered here the desirable target.

The CAT database also includes other scenarios. In particular, the following groups are considered, in order to be compared with the reference elaborated by IPCC/INSTM (red line):

- $\quad 1.5^{\circ} \mathrm{C}$ consistent scenarios (high, median, low; pink lines);

- future emissions under current policies through 2030. The scenarios cover implemented policies at the time of the update, and other developments such as expected economic growth or trends in activity and energy consumption (Figure 3.3, blue lines);

- pledge policies in 2020 are the result of Copenhagen pledges (unconditional and conditional pledges). The effort-sharing bar allows the evaluation of their level of adequacy (Figure 3.3, purple lines).

Regarding the other parameters involved in the optimisation, the ranges are set as indicated in Table 3.1, where the optimised values are also indicated. The ranges of the RES parameters are set between zero and $50 \%$ that is a very high value in term of growth but useful to explore the capability of the MEDEAS model in reaching the target of decarbonisation. Indeed, the 
optimisation response, how could one expect, leads to high values: for example, hydro-electric and solar photovoltaic annual growth reach respectively $30.3 \%$ and $45 \%$. Also, the transportation parameters turn towards an increment of electric and hybrid vehicles. However, it was verified by means the simulations with MEDEAS model, that the transportation policy influences the decarbonisation to a lesser extent than RES parameters (see the sensitivity analysis section).

In Figure 3.1, the result of the fitting is reported and the agreement between the two emission curves expressed in GT (Gigaton) is considerable.

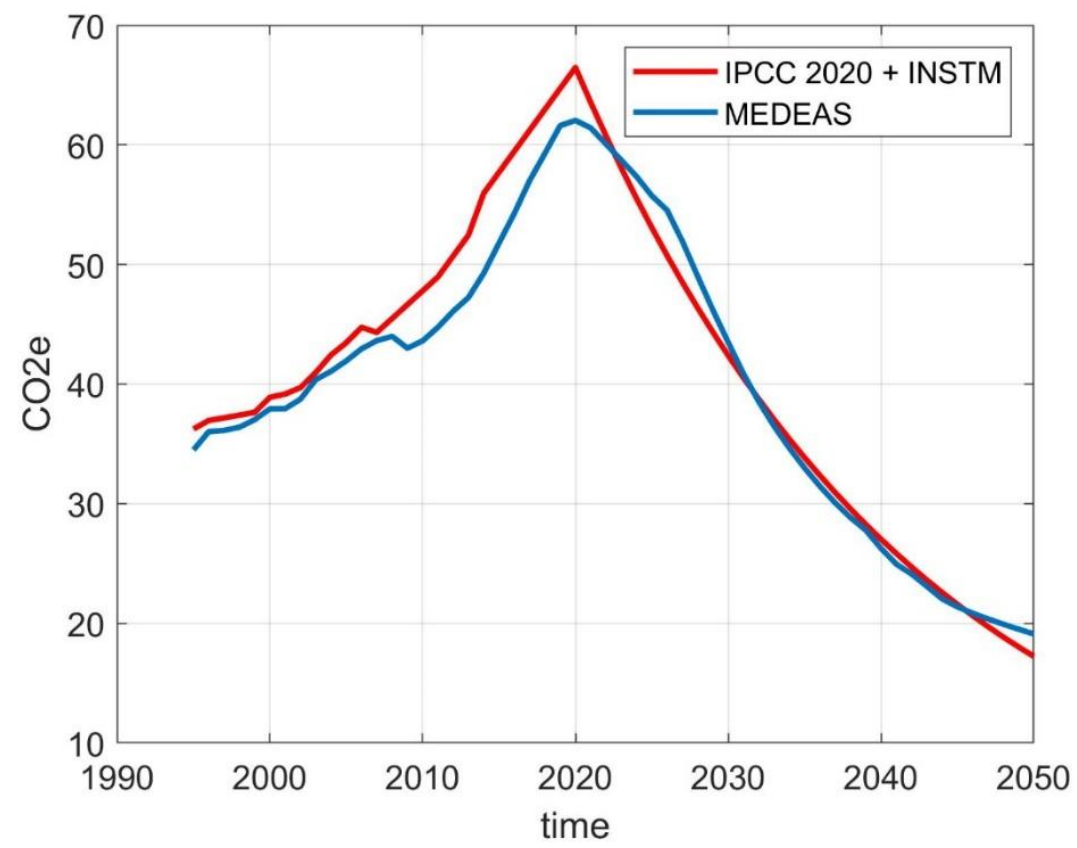

Figure 3.1. Total $\mathrm{CO}_{2}$ equivalent (all GHGs) obtained by SIMPSA optimisation with 39 calibrated parameters.

\begin{tabular}{|c|c|c|}
\hline Parameters & $\begin{array}{c}\text { Optimised values } \\
\text { (Figure 4.3) }\end{array}$ & $\begin{array}{c}\text { Range for the } \\
\text { optimisation }\end{array}$ \\
\hline P hydro growth & $30.3 \%$ & $0-50 \%$ \\
\hline P geot-elec growth & $29.2 \%$ & $0-50 \%$ \\
\hline P solid bioE-elec growth & $17.4 \%$ & $0-50 \%$ \\
\hline P oceanic & $24 \%$ & $0-50 \%$ \\
\hline P onshore wind & $21 \%$ & $0-50 \%$ \\
\hline P wind offshore & $9 \%$ & $0-50 \%$ \\
\hline P solar PV (Photovoltaic) & $45 \%$ & $0-50 \%$ \\
\hline P biofuels 2gen & $15.0 \%$ & $0-50 \%$ \\
\hline P biofuels 3gen & $27.0 \%$ & $0-50 \%$ \\
\hline P bioE residues for heat+elec & $16.0 \%$ & $0-50 \%$ \\
\hline P cellulosic biofuels & $33 \%$ & $0-50 \%$ \\
\hline P waste change & 0.025465277 & $0-0.1$ \\
\hline P BEV (Battery Electric Vehicle) & $28 \%$ & $0-50 \%$ \\
P HEV (Hybrid Electric Vehicle) & $34 \%$ & $0-50 \%$ \\
P NGV (Natural Gas Vehicle) & $8 \%$ & $0-50 \%$ \\
\hline
\end{tabular}




\section{puntCorg}

\begin{tabular}{|c|c|c|}
\hline Parameters & $\begin{array}{c}\text { Optimised values } \\
\text { (Figure 4.3) }\end{array}$ & $\begin{array}{c}\text { Range for the } \\
\text { optimisation }\end{array}$ \\
\hline P PHS (Pumped Hydro Storage) & $20.0 \%$ & $0-50 \%$ \\
P CSP (Concentrated Solar Power) & $41 \%$ & $0-50 \%$ \\
\hline P solar for heat & $29.6 \%$ & $0-50 \%$ \\
\hline P geothermal for heat & $32.2 \%$ & $0-50 \%$ \\
\hline P solid bioE for heat & $14.3 \%$ & $0-50 \%$ \\
\hline Policy electric household 4wheeler vehicle Tfin & 0.52420319 & $0-1$ \\
Policy hybrid household 4w vehicle Tfin & 0.309401608 & $0-1$ \\
Policy gas household vehicle 4w Tfin & 0.031106111 & $0-1$ \\
Policy electric 2wheeler h. Tfin & 0.655017852 & $0-1$ \\
Policy change to 2wheeler h. Tfin & 0.597248823 & $0-1$ \\
\hline Policy hybrid HV Tfin & 0.164336529 & $0-1$ \\
Policy gas HV Tfin & 0.517193803 & $0-1$ \\
Policy electric LV Tfin & 0.243356834 & $0-1$ \\
Policy hybrid LV Tfin & 0.081390031 & $0-1$ \\
Policy gas LV Tfin & 0.496621902 & $0-1$ \\
Policy electric bus Tfin & 0.200234358 & $0-1$ \\
Policy hybrid bus Tfin & 0.680892168 & $0-1$ \\
Policy gas bus Tfin & 0.011117541 & $0-1$ \\
Policy electric train Tfin & 0.887146369 & $0-1$ \\
\hline
\end{tabular}

Table 3.1. All parameters regarding optimisation shown in Figure 3.1, the optimised values in column 2 and the set ranges for the calibration in column 3 are reported.

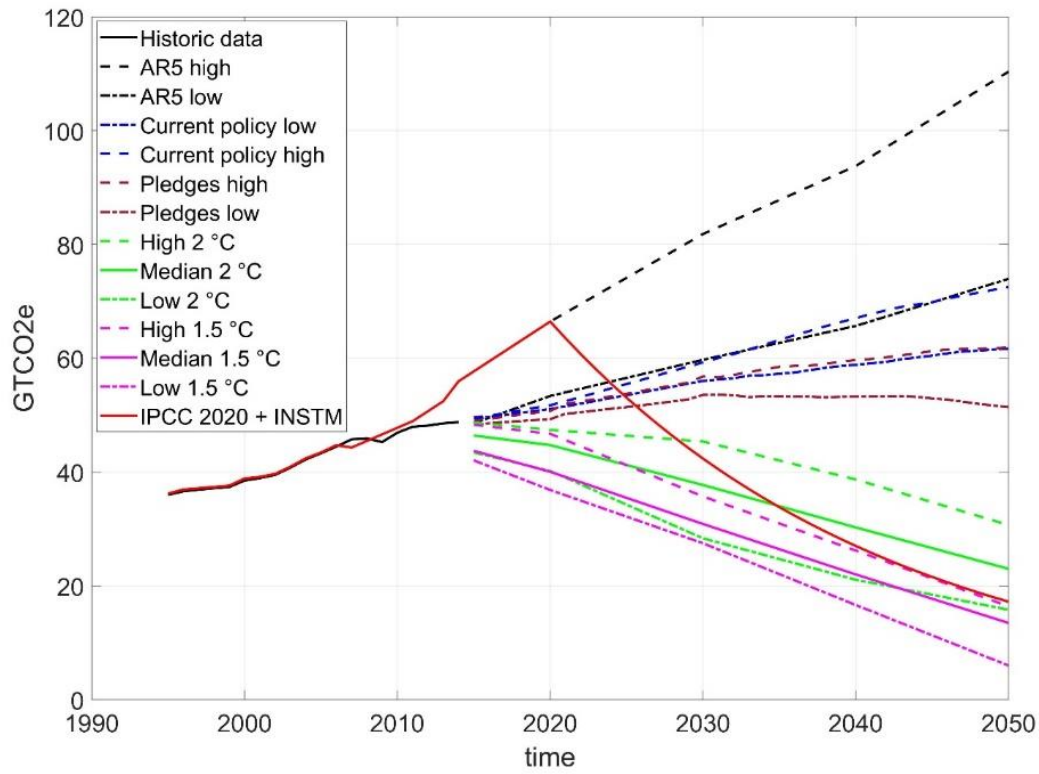

Figure 3.2. The red line is the IPCC2020 + INSTM scenario, the blue line is the MEDEAS simulation of Figure 3.2 but considering GDP of Table 3.1; the dark dashed and dark dashed-dotted are respectively the AR5 BAU high and low; the blue dashed and dark dashed-dotted are respectively the current policy high and low; the purple dashed and dark dashed-dotted are respectively the pledge policy high and low; the green and green dashed are respectively the median and high warming projection $2{ }^{\circ} \mathrm{C}$ consistent; the blue dashed is the optimised MEDEAS simulation according to projection $2{ }^{\circ} \mathrm{C}$ consistent (high); the dark green is warming projection $1.5^{\circ} \mathrm{C}$ consistent, reported for comparison with MEDEAS simulations. 
After having obtained the above preliminary results that represent the first test, other simulations are performed in order to calibrate the warming projection of the $2{ }^{\circ} \mathrm{C}$ consistent scenarios (high, median and low) provided by IPCC. First, the RES parameters are initialised according to the calibration scheme (all initialisation parameters are reported in the Appendix). Then, annual population and GDPpc growth initial values are from the World Data Bank ${ }^{3}$ and both are fit by means of a linear function, in order to have 4 parameters (see Appendix). Moreover, by means of the obtained laws, the GDP and annual population growth are forecasted up to 2050 to complete the MEDEAS model input file for simulation. Summarising, in the calibrations 38 parameters are used, that is, the RES ones and 4 parameters (slopes and intercepts) for the GDPpc and annual population growth.

In Figure 3.3, Figure 3.4, and Figure 3.5, the results of the calibration for three emission scenarios (high, median and low) are respectively reported by means of MEDEAS model and the related (optimised) annual population and GDPpc growth. In Table 3.1 and Table 3.2, the related optimised parameters for all calibrations are shown. One could observe that the RES parameters, on average, increase from high to low warming $2{ }^{\circ} \mathrm{C}$ consistent, as expected, but median is (on average) a little smaller of high. In these three simulations, the ranges of RES parameters are set between 0 and $40 \%$, a maximum value a little more realistic than the first calibration test previously described. For example, the calibrated hydro-electric growth is between $13.2 \%$ (high projection) and $21.2 \%$ (low projection), while solar photovoltaic is between $30 \%$ and $34 \%$. The calibrated parameters are consistent with ones of the previous test. Considering the transportation policy, the search ranges are set in order to implement an electric and hybrid vehicle to increase the decarbonisation, following the trend of the first optimisation test. Moreover, the GDP decreases from high to low warming calibration, the annual population growth increases; this behaviour probably depends on the shape of the error functions, in which the global minimum corresponds to high values of the annual population growth and low values of the GDPpc when the three mentioned optimisations are considered. In summary, the GDPpc and annual population growth influence significantly the model response in term of decarbonisation.

${ }^{3}$ Available online at https://data.worldbank.org (last accessed: April 15, 2019). 


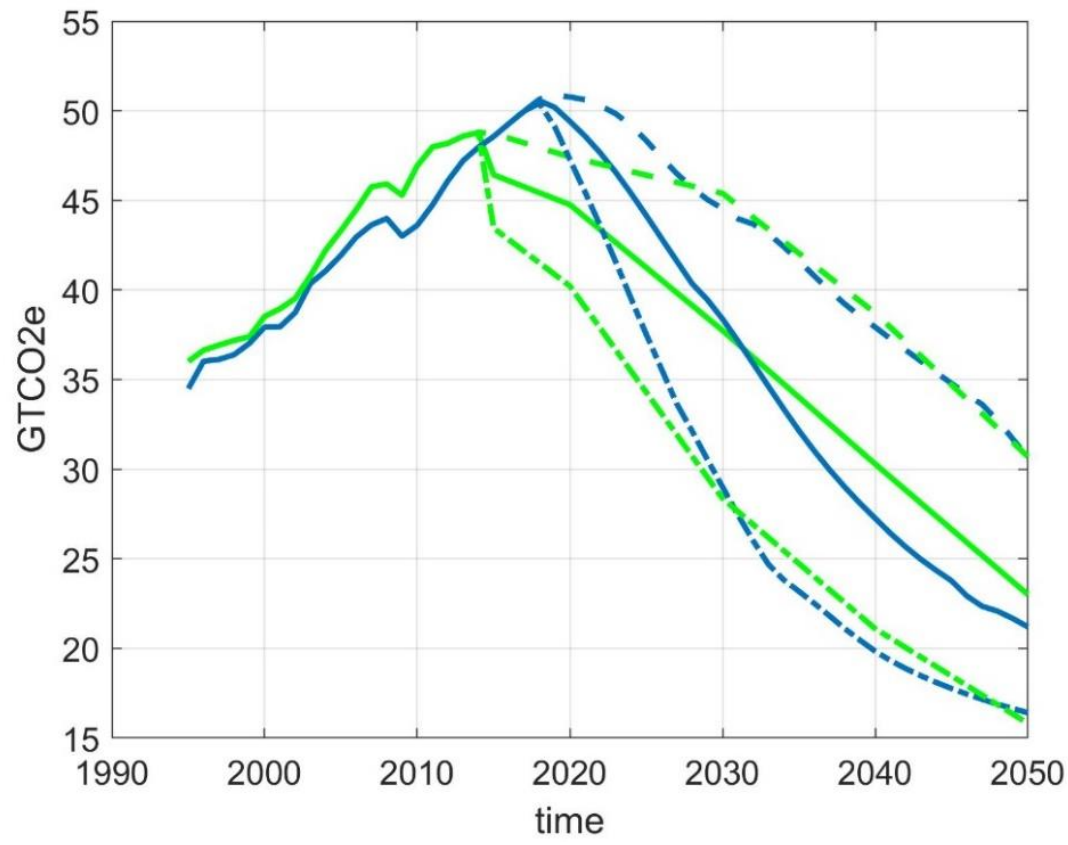

Figure 3.3. Optimisation results: the green curves and blue ones are respectively high IPCC warming projection $2{ }^{\circ} \mathrm{C}$ consistent (dashed green), MEDEAS high optimisation (dashed light blue), median IPCC warming projection $2{ }^{\circ} \mathrm{C}$ consistent (solid green), MEDEAS median optimisation (solid light blue), low IPCC warming projection $2{ }^{\circ} \mathrm{C}$ consistent (dashed-dotted green), MEDEAS low optimisation (dasheddotted light blue). The values of error-functions are respectively (from high to low) 2.423, 6.55 and 9.66.

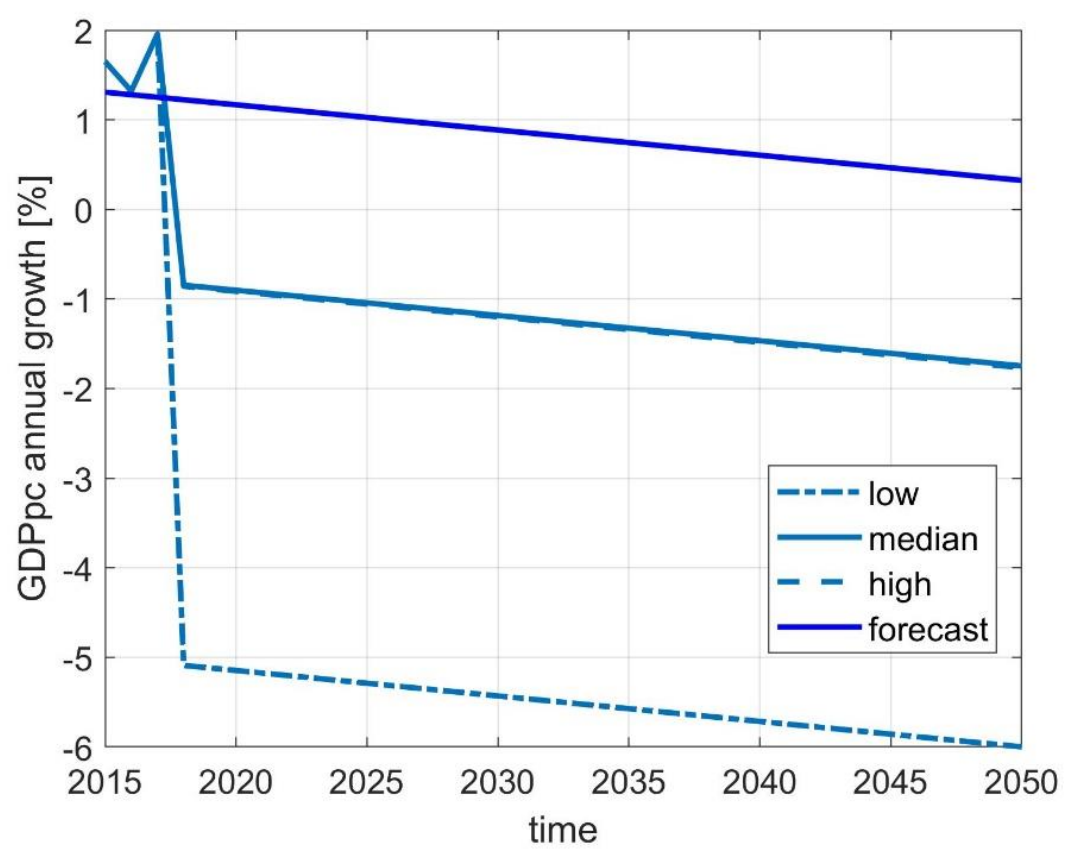

Figure 3.4. The calibrated GDPpc annual growth: the solid light blue corresponds to the forecast up to 2050 (starting from data of World Data Bank) in order to initialise the calibration procedure, the dasheddotted blue is the result from calibration according to the high IPCC warming projection $2{ }^{\circ} \mathrm{C}$ consistent, the solid blue is the result from calibration according to the median IPCC warming projection $2{ }^{\circ} \mathrm{C}$ consistent and the dashed blue is the result from calibration according to the low IPCC warming projection $2{ }^{\circ} \mathrm{C}$ consistent. 


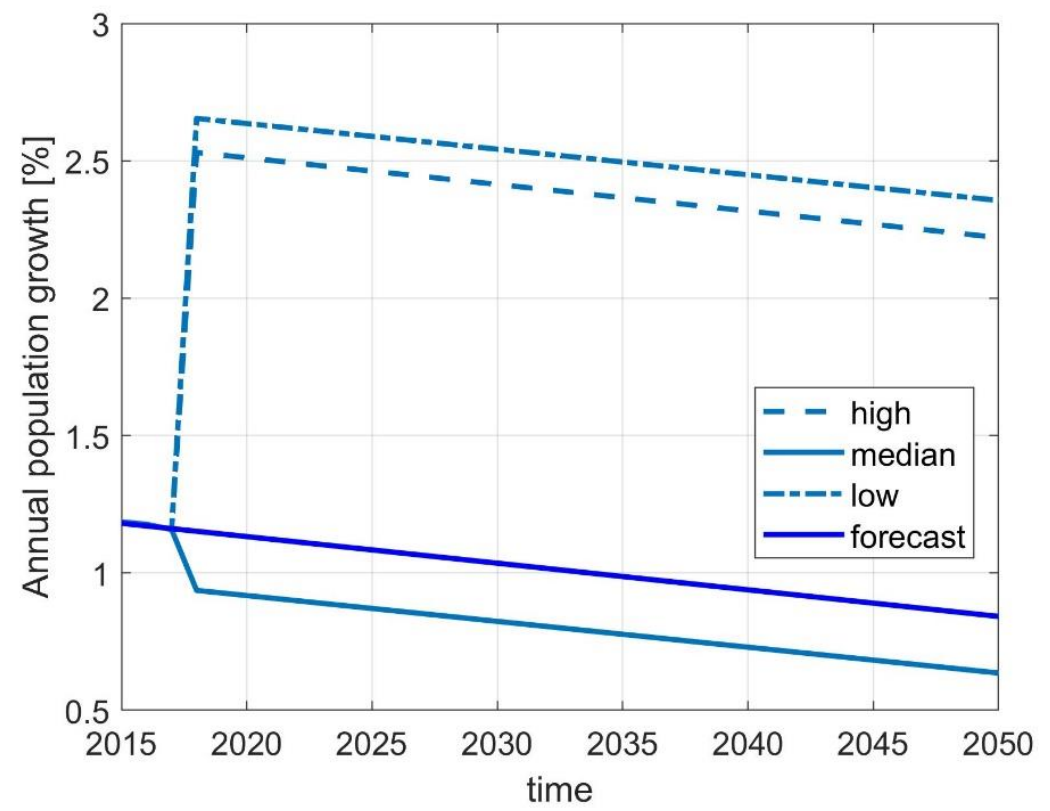

Figure 3.5. The calibrated annual population growth: the solid light blue corresponds to the forecast up to 2050 (starting from data of World Data Bank) in order to initialise the calibration procedure, the dashed-dotted blue is the result from calibration according to the high IPCC warming projection $2{ }^{\circ} \mathrm{C}$ consistent, the solid blue is the result from calibration according to the median IPCC warming projection $2{ }^{\circ} \mathrm{C}$ consistent and the dashed blue is the result from calibration according to the low IPCC warming projection $2{ }^{\circ} \mathrm{C}$ consistent.

\begin{tabular}{|l|c|c|c|c|}
\hline Parameters & $\begin{array}{c}\text { Optimised } \\
\text { values IPCC } \\
\text { High }\end{array}$ & $\begin{array}{c}\text { Optimised } \\
\text { values IPCC } \\
\text { Median }\end{array}$ & $\begin{array}{c}\text { Optimised } \\
\text { values IPCC } \\
\text { Low }\end{array}$ & $\begin{array}{c}\text { Fixed ranges } \\
\text { for the } \\
\text { optimisation }\end{array}$ \\
\hline hydro growth & $13.2 \%$ & $18.9 \%$ & $21.2 \%$ & $0-40 \%$ \\
\hline geot-elec growth & $29.9 \%$ & $6.4 \%$ & $1.3 \%$ & $0-40 \%$ \\
\hline solid bioE-elec growth & $9.5 \%$ & $6.5 \%$ & $10.1 \%$ & $0-40 \%$ \\
\hline oceanic & $5 \%$ & $10 \%$ & $11 \%$ & $0-40 \%$ \\
\hline onshore wind & $18 \%$ & $12 \%$ & $26 \%$ & $0-40 \%$ \\
\hline wind offshore & $11 \%$ & $14 \%$ & $14 \%$ & $0-40 \%$ \\
\hline solar PV (Photovoltaic) & $33 \%$ & $30 \%$ & $34 \%$ & $0-40 \%$ \\
\hline biofuels 2gen & $9 \%$ & $1 \%$ & $14 \%$ & $0-40 \%$ \\
\hline biofuels 3gen & $16 \%$ & $23 \%$ & $19 \%$ & $0-40 \%$ \\
\hline bioE residues for heat+elec & $18 \%$ & $8 \%$ & $5 \%$ & $0-40 \%$ \\
\hline cellulosic biofuels & $22 \%$ & $16 \%$ & $8 \%$ & $0-40 \%$ \\
\hline waste change & 0.0375 & 0.087 & 0.08 & $0-0.1$ \\
\hline BEV (Battery Electric Vehicle) & $15 \%$ & $20 \%$ & $26 \%$ & $0-40 \%$ \\
HEV (Hybrid Electric Vehicle) & $25 \%$ & $24 \%$ & $26 \%$ & $0-40 \%$ \\
NGV (Natural Gas Vehicle) & $8 \%$ & $5 \%$ & $7 \%$ & $0-40 \%$ \\
\hline PHS (Pumped Hydro Storage) & $12.1 \%$ & $13.7 \%$ & $24 \%$ & $0-40 \%$ \\
CSP (Concentrated Solar Power) & $19 \%$ & $24 \%$ & $25 \%$ & $0-40 \%$ \\
\hline solar for heat & $37.3 \%$ & $20 \%$ & $16.4 \%$ & $0-40 \%$ \\
\hline geothermal for heat & $4.5 \%$ & $22.3 \%$ & $12.8 \%$ & $0-40 \%$ \\
\hline solid bioE for heat & $11.6 \%$ & $12.4 \%$ & $24.7 \%$ & $0-40 \%$ \\
\hline
\end{tabular}


Table 3.1. Obtained RES parameters from the calibration scenarios high, median and low warming projection $2{ }^{\circ} \mathrm{C}$ consistent.

\begin{tabular}{|l|c|c|c|c|}
\hline Parameters & $\begin{array}{c}\text { Optimised } \\
\text { values } \\
\text { IPCC High }\end{array}$ & $\begin{array}{c}\text { Optimised } \\
\text { values IPCC } \\
\text { Median }\end{array}$ & $\begin{array}{c}\text { Optimised } \\
\text { values } \\
\text { IPCC Low }\end{array}$ & Ranges \\
\hline Policy electric household 4wheeler vehicle Tfin & 0.392762349 & 0.358323364 & 0.43622925 & $0.25-0.5$ \\
Policy hybrid household 4w vehicle Tfin & 0.266355049 & 0.237260522 & 0.235172001 & $0.2-0.3$ \\
Policy gas household vehicle 4w Tfin & 0.151670479 & 0.149748334 & 0.144501054 & $0.1-0.2$ \\
Policy electric 2wheeler h. Tfin & 0.976435414 & 0.960548833 & 0.970416746 & $0.9-1$ \\
Policy change to 2wheeler h. Tfin & 0.589747363 & 0.612476454 & 0.593670363 & $0.5-0.7$ \\
\hline Policy hybrid HV Tfin & 0.706706735 & 0.677830554 & 0.744115351 & $0.5-0.8$ \\
Policy gas HV Tfin & 0.151037035 & 0.127825973 & 0.161442129 & $0.1-0.2$ \\
Policy electric LV Tfin & 0.428289168 & 0.35085463 & 0.468888008 & $0.3-0.5$ \\
Policy hybrid LV Tfin & 0.193439397 & 0.209949917 & 0.168274521 & $0.15-0.3$ \\
Policy gas LV Tfin & 0.194992338 & 0.167638513 & 0.166511669 & $0.1-0.2$ \\
Policy electric bus Tfin & 0.409098992 & 0.413108197 & 0.424847501 & $0.3-0.45$ \\
Policy hybrid bus Tfin & 0.413501323 & 0.401079742 & 0.428476466 & $0.3-0.45$ \\
Policy gas bus Tfin & 0.078286012 & 0.069260505 & 0.082113826 & $0.05-0.1$ \\
Policy electric train Tfin & 0.863405753 & 0.798483824 & 0.813145664 & $0.7-0.9$ \\
\hline
\end{tabular}

Table 3.2. Obtained transportation policy parameters from the calibration scenarios high, median and low warming projection $2{ }^{\circ} \mathrm{C}$ consistent.

\section{Sensitivity analysis}

In this section, the results related to sensitivity analysis are shown. A first simulation varying only the RES parameters, that is, without handle GDPpc or the annual population growth, is considered in order to reach the maximum decarbonisation; the simulation is set with values obtained in the median calibration, values that are not far from the ones following the forecast based on the past trend. An increment step of $2 \%$ of all RES parameters for every single simulation of the MEDEAS model (up to reach 50\%) is considered (see Table 4.1). The results are illustrated in Figure 4.1, which shows a comparison between the optimised MEDEAS curves corresponding to the three IPCC levels and ones obtained by means of $2 \%$ increment of the RES parameters. As mentioned, starting to the value of GDPpc and annual population growth according to median warming $2{ }^{\circ} \mathrm{C}$ consistent scenario (obtained from model calibration) and concurrently varying the RES parameters from 0 to $50 \%$ (step equal to $2 \%$ ), it is not possible to reach the low configuration (see Figure 4.1). Moreover, in this analysis, the parameters involved in the transportation are not considered due to the minor influence on GHG emission trend (almost negligible) in comparison to the other parameters. Indeed, the electric vehicle policy parameters are imposed at the maximum value, equal to one, without obtaining important changes (see the dotted blue curve in Figure 4.1). While considering again the median model configuration but varying the GDPpc (performing sensitivity analysis related to this parameter), it is possible to reach the low configuration (see Figure 4.2). In Figure 4.3 , the sensitivity results on the annual population growth applying the same methodology for GDPpc are shown, that is, all the parameters obtained from median optimisation are set, and only the annual population growth is varied. Noting that the results of Figure 4.2 and Figure 4.3 are similar, but the ranges of GDPpc and annual population growth are different (see Appendix). In particular, the range of annual population growth (to obtain the same 
results, varying GDPpc, in term of GHG emissions) is larger than GDPpc one compared to the same optimised curves.

\begin{tabular}{|l|c|}
\hline Parameters & $\Delta=\mathbf{2} \%$ \\
\hline hydro growth & $0-50 \%$ \\
\hline geot-elec growth & $0-50 \%$ \\
\hline solid bioE-elec growth & $0-50 \%$ \\
\hline Oceanic & $0-50 \%$ \\
\hline onshore wind & $0-50 \%$ \\
\hline wind offshore & $0-50 \%$ \\
\hline solar PV (Photovoltaic) & $0-50 \%$ \\
\hline biofuels 2gen & $0-50 \%$ \\
\hline biofuels 3gen & $0-50 \%$ \\
\hline bioE residues for heat+elec & $0-50 \%$ \\
\hline cellulosic biofuels & $0-50 \%$ \\
\hline waste change & $0-0.1$ \\
\hline BEV (Battery Electric Vehicle) growth & $0-50 \%$ \\
HEV (Hybrid Electric Vehicle) growth & $0-50 \%$ \\
NGV (Natural Gas Vehicle) growth & $0-50 \%$ \\
\hline PHS (Pumped Hydro Storage) & $0-50 \%$ \\
CSP (Concentrated Solar Power) & $0-50 \%$ \\
\hline solar for heat & $0-50 \%$ \\
\hline geothermal for heat & $0-50 \%$ \\
\hline solid bioE for heat & $0-50 \%$ \\
\hline
\end{tabular}

Table 4.1. The parameters (RES annual growth) involved in the sensitivity analysis: for each simulation an increment of $2 \%$ for all parameters, with exclusion of waste change parameter that vary from 0 to 0.1 with step equal to 0.004 , is considered. 


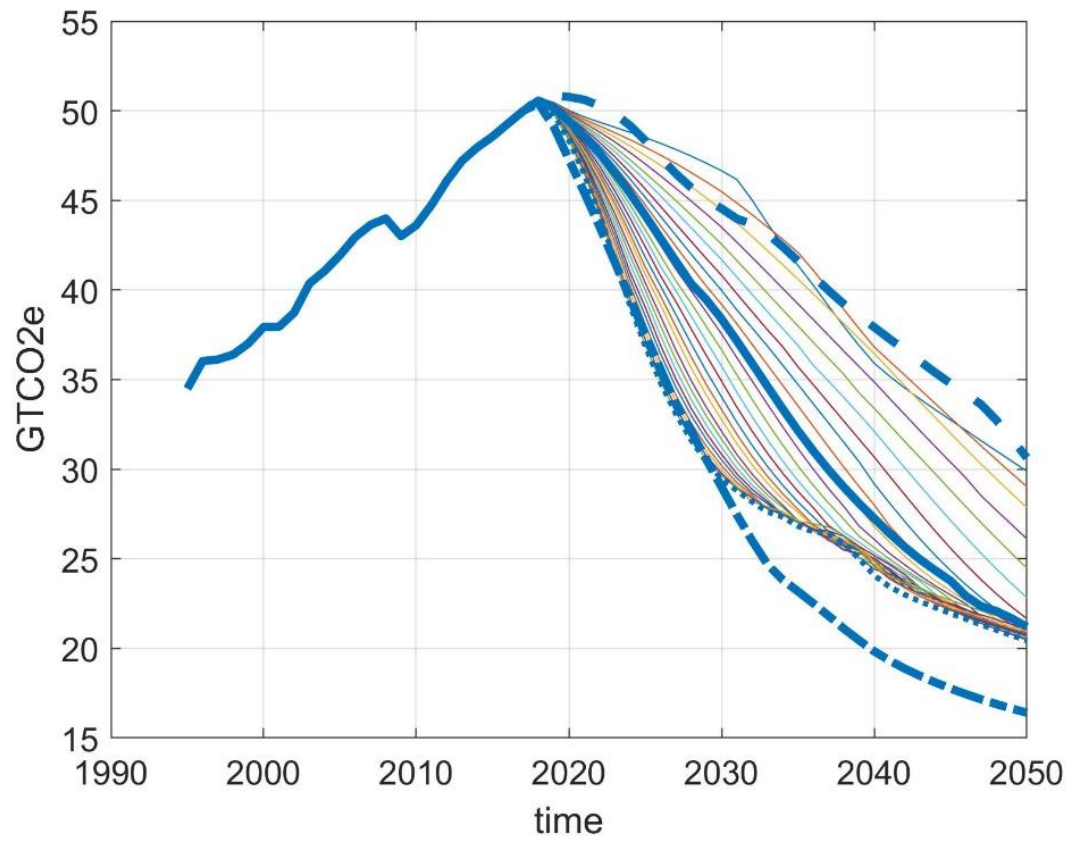

Figure 4.1. Sensitivity analysis according to RES parameters reported in Table 4.1. The blue dashed, solid and dashed-dotted correspond to calibrated output of the MEDEAS model according respectively with high, median and low warming $2{ }^{\circ} \mathrm{C}$ consistent; the dotted curve represents the last one with $50 \%$ RES parameter values and maximising the transportation parameters (the obtained gain is relatively small).

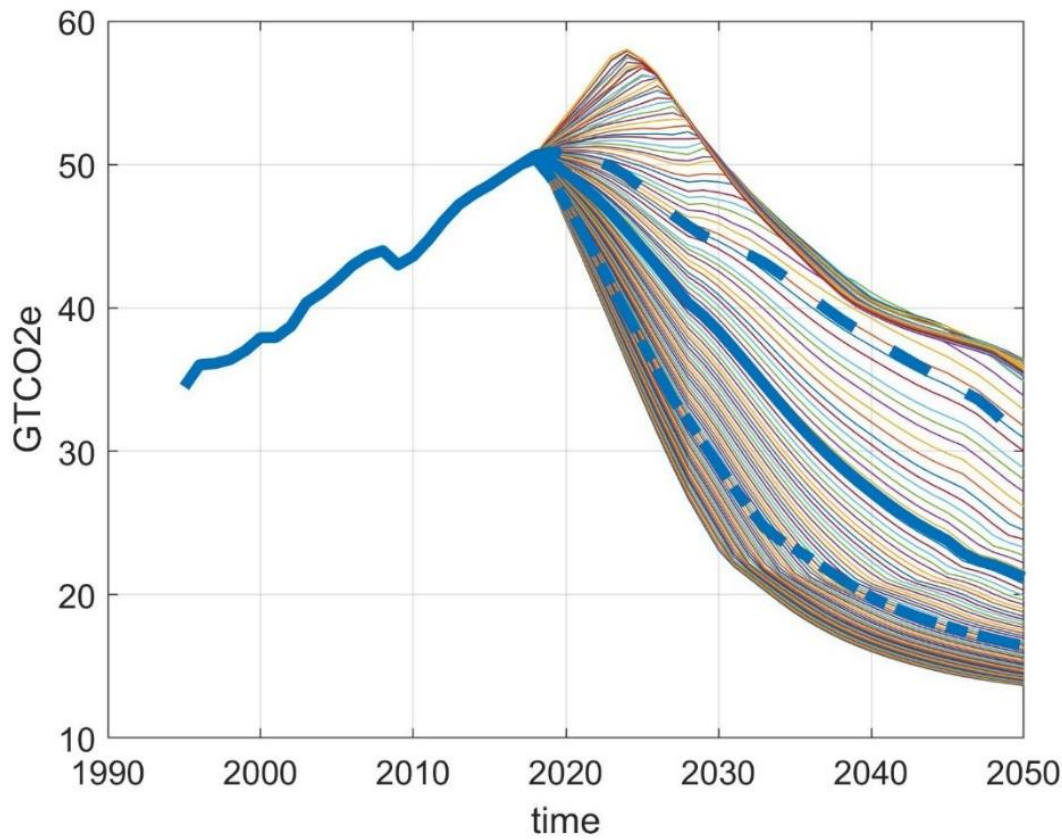

Figure 4.2. Sensitivity analysis according to GDPpc variations reported in Appendix. The dashed, solid and dashed-dotted blue lines correspond to calibrated output of the MEDEAS model according respectively to high, median and low warming $2{ }^{\circ} \mathrm{C}$ consistent. 


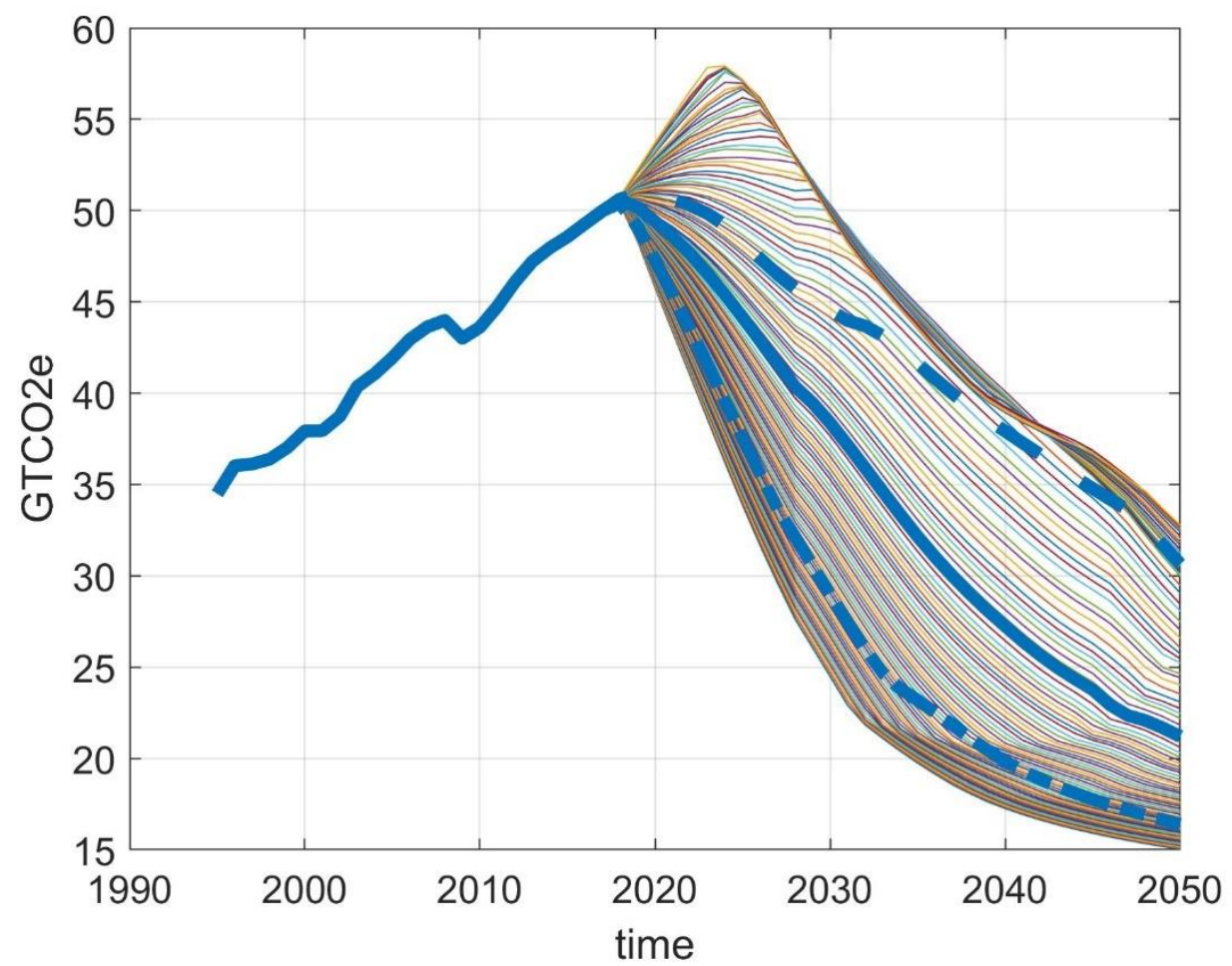

Figure 4.3. Sensitivity analysis according to annual population growth variations reported in Appendix. The dashed, solid and dashed-dotted blue lines correspond to calibrated output of the MEDEAS model according respectively with high, median and low warming $2{ }^{\circ} \mathrm{C}$ consistent.

\section{Discussion}

In this work, the optimisation algorithm for Python MEDEAS World (pmedeas_w) is developed to study what are the main parameters responsible for fitting GHG emission IPCC/INSTM pathways. Moreover, it is considered that, from 2020, the global temperature will stay below $2^{\circ} \mathrm{C}$ until 2050 and the remaining carbon budget will not exceed 1494 GtCO2eq.

In this first stage, the calibration procedure works on 39 selected parameters (those that influence directly the GHG emissions) of 4000 variables counted in pymedeas_w, reaching to match the curve IPCC+ INSTM. Going more in-depth, the used parameters are three for GDPpc, two for the population growth and 34 for RES and transportation parameters. From calibration, both GDPpc and the annual population growth decrease until 2025 remaining positive but becoming negative after 2025. In particular, the optimised RES parameters increase the $\%$ of hydro growth and \% geot-elec growth of about ten times in comparison to the BAU while the \% solar PV of about 3 times (Table 3.1). Through this first analysis, it has been demonstrated that a huge effort is needed to reach the $2^{\circ} \mathrm{C}$ goal, especially in terms of primary energy production (which should be covered completely from renewable energies before 2050) that must undertake a rapid increase. This increment is particularly strong, implying that a new economic arrangement not based on an unconditioned 'growth' might be the solution to reach a decarbonised age together with a slight reduction of the GDPpc and population growth. 
Moreover, a second calibration analysis using as reference the GHG emissions curves (high, medium and low) of IPCC $2^{\circ} \mathrm{C}$-consistent scenarios has been performed. The choice to use IPCC scenarios was due to test the newly assembled pymedeas_w in order to discover what are the main sensible parameters implied in the process of decarbonisation. Three optimisations of the MEDEAS model to fit the high, medium and low GHG pathways developed by IPCC were run, considering 38 parameters, including RES and transportation ones and four parameters for the GDPs and annual population growth. MEDEAS median calibration seemed to be more feasible in terms of \% annual population and GDPpc growth trends, which resulted in not being so distant to the actual forecast. However, it is correct to assert that is not simple to solve an optimisation problem considering a complex model as MEDEAS and, therefore, many parameters involved in the calibration.

\section{Conclusions}

A new methodology, applied in general to System Dynamics model, for building scenarios trying to fit 2020 decarbonisation scenarios has been proposed for the Python Version of MEDEAS world (pmedeas_w) using optimisation algorithms developed in the MATLAB® environment. The methodology is still under development, anyway preliminary results show the promising use of pymedeas_w interface with other platforms, especially in the view to use MEDEAS not only as models to explore simulated scenarios but also as models to fit scenarios (IPCC) or experimental data. The IPCC emission scenarios represent the decarbonisation trends to reach the global warming of $2^{\circ} \mathrm{C}$ in the year 2050. Fitting IPCC scenario with MEDEAS model we solve an inverse problem, that is, we search the parameters of the MEDEAS model (for example, the annual growth of the RES) useful to realise an optimal transition following a decarbonisation program (represented by the IPCC curves). However, to reproduce theoretical scenarios in a large parameter domain, it is necessary to investigate the reliability of the values of the involved parameters, first of all, GDP and RES growth, to which the model presents a certain sensibility.

In particular, the sensibility of the GDP variable is due to the MEDEAS model approach in linking the economy and the energy modules, connected to provide dynamic adaptive scenarios. In most of the Integrated Assessment Models, used, for instance, by IPCC, energy supply is no subject to limits; thus, the results underestimate the real effects of resources' scarcity on GDP. Thanks to the MEDEAS model peculiarity, that provides feedbacks between economy and energy availability, it is possible to cover the lack of consideration of energy and resources scarcity on the economy, and, in addition to the initial conditions imposed by the framework of the exogenous scenario, the results are endogenously adapted to account for energy and resources physical limits.

All our simulations show that is necessary to strongly implement the renewable technologies, limit the population growth and decrease the annual rate of GDP growth, that which in any case means not reducing general well-being.

Moreover, starting from the achieved parameters, it is possible to build a new theoretical scenario of the MEDEAS model. Obviously, the realisation in practice must be evaluated, that is, the interpretation of the results must be made with caution. MEDEAS-World is not intended to predict the future, but rather to qualitatively guide the best options for the energy transition towards a low carbon economy. 


\section{Acknowledgements}

We acknowledge the support of MEDEAS project through the funding from the European Union's Horizon 2020 research and innovation programme under grant agreement No 691287. The authors thank Iñigo Capellán-Pérez and Margarita Mediavilla for stimulating discussion and for their suggestions.

\section{Reference list}

Capellán-Pérez, I., de Castro, C., and Arto, I. (2017a), “Assessing Vulnerabilities and Limits in the Transition to Renewable Energies: Land Requirements under 100\% Solar Energy Scenarios", Renewable and Sustainable Energy Reviews, 77: 760-782.

Capellán-Pérez, I., de Blas, I., Nieto, J., de Castro, C., Miguel, L.J., Mediavilla, M., Carpintero, Ó., Rodrigo, P., Frechoso, F., and Cáceres, S. (2017b), Modelling Sustainable Energy System Development under Environmental and Socioeconomic Constraints. MEDEAS Scenarios D4.1. Available online at https:/www.medeas.eu/deliverables/ (last accessed: April 15, 2019).

Capellán-Pérez, I., de Blas, I., Nieto, J., de Castro, C., Miguel, L.J., Carpintero, Ó., Mediavilla, M., Lobejón, L.F., Ferreras-Alonso, N., Rodrigo, P., Frechoso, F.A.F., and Álvarez-Antelo, D. (2019a), “MEDEAS: A New Modelling Framework Integrating Global Biophysical and Socioeconomic Constraints", Manuscr. Submitt. Publ.

Capellán-Pérez, I., Blas De, I., Nieto, J., de Castro, C., Carpintero, Ó., Miguel, L.J., and Mediavilla, M. (2019b), “MEDEAS: A New Modelling Framework Integrating Biophysical and Socioeconomic Constraints", Global Environmental Change.

Cardoso, M.F. (1996), “The Simplex-Simulated Annealing Approach to Continuous NonLinear Optimization", Computers \& Chemical Engineering, 20 (9): 1065-1080.

Diaz, D., and Moore, F. (2017), "Quantifying the Economic Risks of Climate Change", Nature Climate Change, 7 (11): 774-782.

Dietz, S., and Stern, N. (2015), “Endogenous Growth, Convexity of Damage and Climate Risk: How Nordhaus' Framework Supports Deep Cuts in Carbon Emissions", The Economic Journal, 125 (583): 574-620.

Dorfman, R. (1969), "An Economic Interpretation of Optimal Control Theory", American Economic Review, 59 (5): 817-831.

Marsili-Libelli, S. (1992), "Parameter Estimation of Ecologicals Models”, Ecological Modelling, 62 (4): 233-258.

Martelloni, G., Segoni, S., Lagomarsino, D., Fanti, R., and Catani, F. (2013), "Snow Accumulation/Melting Model (SAMM) for Integrated Use in Regional Scale Landslide Early Warning Systems", Hydrology and Earth System Sciences, 17 (3): 1229-1240.

Meinshausen, M., Raper, S.C.B., and Wigley, T.M.L. (2011), "Emulating Coupled AtmosphereOcean and Carbon Cycle Models with a Simpler Model, MAGICC6 - Part 1: Model 
Description and Calibration", Atmospheric Chemistry and Physics, 11: 1417-1456. DOI: 10.5194/acp-11-1417-2011.

Nelder, J.A., and Mead, R. (1965), "A Simplex Method for Function Minimization", The Computer Journal, 7 (4): 308-313. DOI: 10.1093/comjnl/7.4.308.

Perissi, I., Falsini, S., Bardi, U., Natalini, D., Green, M., Jones, A., and Solé, J. (2018), “Potential European Emissions Trajectories within the Global Carbon Budget", Sustainability, 10 (11): 1-13.

Pfenninger, S., DeCarolis, J., Hirth, L., Quoilin, S., and Staffell, I. (2017), “The Importance of Open Data and Software: Is Energy Research Lagging Behind?", Energy Policy, 101: 211215. DOI: 10.1016/j.enpol.2016.11.046.

Ringkjøb, H.K., Haugan, P.M., and Solbrekke, I.M. (2018), “A Review of Modelling Tools for Energy and Electricity Systems with Large Shares of Variable Renewables", Renewable and Sustainable Energy Reviews, 96: 440-459. DOI: 10.1016/j.rser.2018.08.002.

Rotmans, J., and van Asselt, M.B. (2001), “Uncertainty in Integrated Assessment Modelling: A Labyrinthic Path", Integrated Assessment, 2 (2): 43-55. DOI: 10.1023/A:1011588816469.

Santarlasci, A., Martelloni, G., Frizzi, F., Santini, G., and Bagnoli, F. (2014), "Modeling Warfare in Social Animals: A 'Chemical' Approach", PloS One, 9 (11): 1-12.

Scrieciu, S., Rezai, A., and Mechler, R. (2013), “On the Economic Foundations of Green Growth Discourses: The Case of Climate Change Mitigation and Macroeconomic Dynamics in Economic Modeling", Wiley Interdisciplinary Reviews: Energy and Environment, 2 (3): 251268. DOI: 10.1002/wene.57.

Solé, J., García-Olivares, A., Turiel, A., and Ballabrera-Poy, J. (2018), “Renewable Transitions and the Net Energy from Oil Liquids: A Scenarios Study", Renewable Energy, 116: 258271.

Wigley, T., and Raper, S. (1992), "Implications for Climate and Sea Level of Revised IPCC Emissions Scenarios", Nature, 357: 293-300. DOI: 10.1038/357293a0.

Solé, J., Samsó, R., García-Ladona, E., García-Olivares, A., Ballabrera, J., Madurell, T., Turiel, A., Osychenko, O., Álvarez, D., Bardi, U., Baumann, M., Buchmann, K., Capellán-Pérez, Í., Cerny, M., Carpintero, Ó., de Blas, I., de Castro, C., de Lathouwer, J.-D., Duce, C., Eggler, L., Enríquez, J.M., Falsini, S., Feng, K., Ferreras, N., Frechoso, F., Hubacek, K., Jones, A., Kaclíková, R., Kershner, C., Kimmich, C., Lobejón, L.F., Lomas, P.L., Martelloni, G., Mediavilla, M., Miguel, L.J., Natalini, D., Nieto, J., Nikolaev, A., Parrado, G., Papagianni, S., Perissi, I., Ploiner, C., Radulov, L., Rodrigo, P., Sun, L., and Theofilidi, M. (2019), "Modelling the Renewable Transition: Scenarios and Pathways for a Decarbonised Future Using Pymedeas, a New Open-Source Energy Systems Model", Manuscr. Submitt. Publ.

\section{APPENDIX}




\begin{tabular}{|l|c|l|c|}
\hline Parameters & Initial values & Parameters & Initial values \\
\hline hydro growth & $2.8 \%$ & solar for heat & $10 \%$ \\
\hline geot-elec growth & $2.4 \%$ & geothermal for heat & $7.7 \%$ \\
\hline solid bioE-elec growth & $7.2 \%$ & solid bioE for heat & $6.3 \%$ \\
\hline oceanic & $10 \%$ & $\begin{array}{l}\text { Policy electric household } \\
\text { 4wheeler vehicle Tfin }\end{array}$ & 0.0064 \\
\hline onshore wind & $15 \%$ & $\begin{array}{l}\text { Policy hybrid household } \\
\text { 4w vehicle Tfin }\end{array}$ & 0.0108 \\
\hline wind offshore & $15 \%$ & $\begin{array}{l}\text { Policy gas household } \\
\text { vehicle 4w Tfin }\end{array}$ & 0.1489 \\
\hline solar PV (Photovoltaic) & $15 \%$ & $\begin{array}{l}\text { Policy electric } 2 \text { wheeler } \\
\text { h. Tfin }\end{array}$ & 0.9254 \\
\hline biofuels 2gen & $5 \%$ & $\begin{array}{l}\text { Policy change to } \\
\text { 2wheeler h. Tfin }\end{array}$ & 0.3325 \\
\hline biofuels 3gen & $5 \%$ & $\begin{array}{l}\text { Policy hybrid HV (heavy } \\
\text { vehicles) Tfin }\end{array}$ & 0.00045 \\
\hline bioE residues for heat+elec & $5 \%$ & Policy gas HV Tfin & 0.00045 \\
\hline cellulosic biofuels & $8 \%$ & $\begin{array}{l}\text { Policy electric LV (light } \\
\text { cargo vehicles) Tfin }\end{array}$ & 0.00074 \\
\hline waste change & 0.04436 & Policy hybrid LV Tfin & 0.00036 \\
\hline BEV (Battery Electric Vehicle) growth & $9 \%$ & Policy gas LV Tfin & 0.01597 \\
\hline HEV (Hybrid Electric Vehicle) growth & $9 \%$ & Policy electric bus Tfin & 0 \\
\hline NGV (Natural Gas Vehicle) growth & $7 \%$ & Policy hybrid bus Tfin & 0 \\
\hline PHS (Pumped Hydro Storage) & $2.3 \%$ & Policy gas bus Tfin & 0 \\
\hline CSP (Concentrated Solar Power) & $10 \%$ & Policy electric train Tfin & 0.2 \\
\hline
\end{tabular}

Table 1A. Initial values of parameters used for the first calibration test (related to IPCC+INSTM scenario).

\begin{tabular}{|l|c|c|c|}
\hline Parameters & High & Median & Low \\
\hline hydro growth & $10 \%$ & $20 \%$ & $25 \%$ \\
\hline geot-elec growth & $4.8 \%$ & $4.8 \%$ & $4.8 \%$ \\
\hline solid bioE-elec growth & $14.4 \%$ & $14.4 \%$ & $14.4 \%$ \\
\hline oceanic & $15 \%$ & $15 \%$ & $15 \%$ \\
\hline onshore wind & $20 \%$ & $20 \%$ & $20 \%$ \\
\hline wind offshore & $20 \%$ & $20 \%$ & $20 \%$ \\
\hline solar PV (Photovoltaic) & $8 \%$ & $8 \%$ & $8 \%$ \\
\hline biofuels 2gen & $8 \%$ & $8 \%$ & $8 \%$ \\
\hline biofuels 3gen & $8 \%$ & $8 \%$ & $8 \%$ \\
\hline bioE residues for heat+elec & $8 \%$ & $8 \%$ & $8 \%$ \\
\hline cellulosic biofuels & $8 \%$ & $8 \%$ & $8 \%$ \\
\hline waste change & 0.04436 & 0.04436 & 0.04436 \\
\hline BEV (Battery Electric Vehicle) & $10 \%$ & $20 \%$ & $25 \%$ \\
HEV (Hybrid Electric Vehicle) & $10 \%$ & $20 \%$ & $25 \%$ \\
NGV (Natural Gas Vehicle) & $5 \%$ & $5 \%$ & $10 \%$ \\
\hline PHS (Pumped Hydro Storage) & $10 \%$ & $20 \%$ & $25 \%$ \\
CSP (Concentrated Solar Power) & $10 \%$ & $20 \%$ & $25 \%$ \\
\hline solar for heat & $10 \%$ & $20 \%$ & $25 \%$ \\
\hline geothermal for heat & $10 \%$ & $20 \%$ & $25 \%$ \\
\hline solid bioE for heat & $10 \%$ & $20 \%$ & $25 \%$ \\
\hline
\end{tabular}




\section{puntoorg}

Table 2A. Initial values of RES parameters used for the calibration related to the IPCC scenarios high, median and low warming projection $2{ }^{\circ} \mathrm{C}$ consistent.

\begin{tabular}{|l|c|c|c|}
\hline Parameters & High & Median & Low \\
\hline Policy electric household 4wheeler vehicle Tfin & 0.38 & 0.38 & 0.45 \\
Policy hybrid household 4w vehicle Tfin & 0.25 & 0.25 & 0.25 \\
Policy gas household vehicle 4w Tfin & 0.15 & 0.15 & 0.15 \\
Policy electric 2wheeler h. Tfin & 0.95 & 0.95 & 0.98 \\
Policy change to 2wheeler h. Tfin & 0.6 & 0.6 & 0.6 \\
\hline Policy hybrid HV Tfin & 0.7 & 0.7 & 0.75 \\
Policy gas HV Tfin & 0.15 & 0.15 & 0.15 \\
Policy electric LV Tfin & 0.4 & 0.4 & 0.45 \\
Policy hybrid LV Tfin & 0.2 & 0.2 & 0.2 \\
Policy gas LV Tfin & 0.15 & 0.15 & 0.15 \\
Policy electric bus Tfin & 0.4 & 0.4 & 0.42 \\
Policy hybrid bus Tfin & 0.4 & 0.4 & 0.4 \\
Policy gas bus Tfin & 0.08 & 0.08 & 0.08 \\
Policy electric train Tfin & 0.8 & 0.8 & 0.85 \\
\hline
\end{tabular}

Table 3A. Initial values of transportation policy parameters used for the calibration related to the IPCC scenarios high, median and low warming projection $2{ }^{\circ} \mathrm{C}$ consistent.

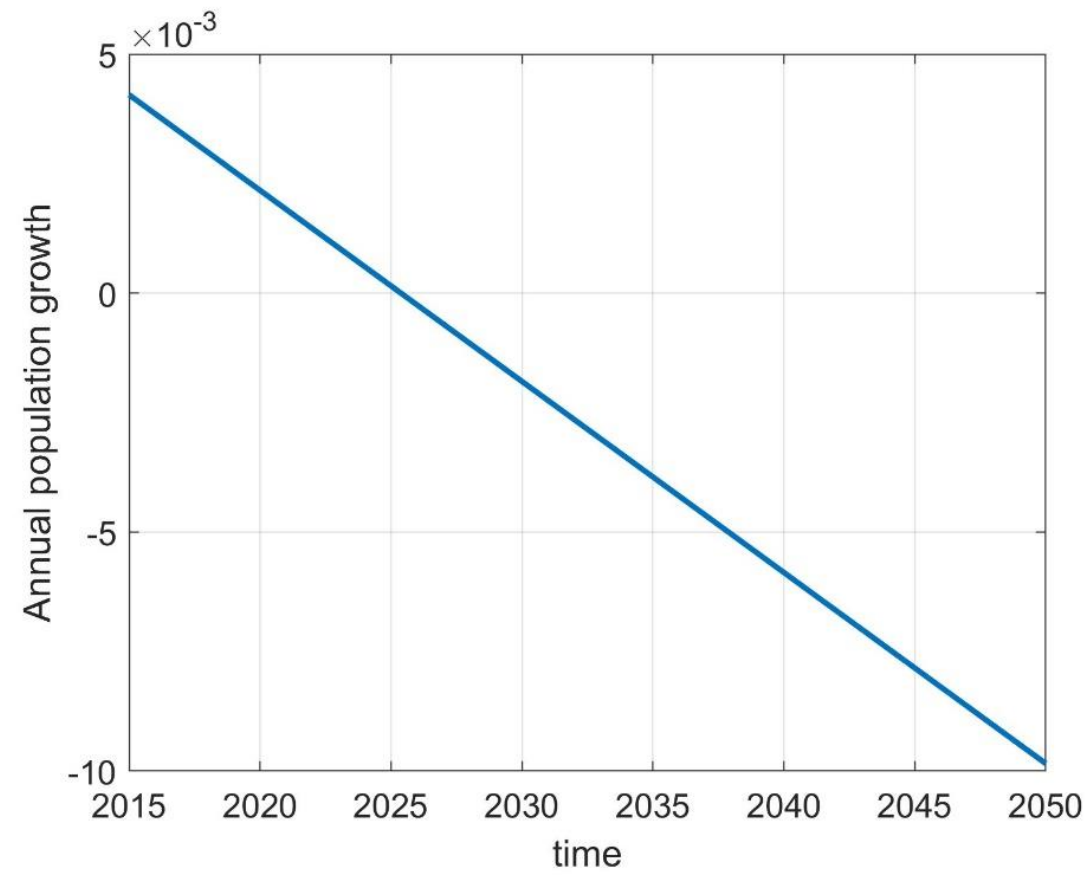

Figure 1A. Annual population growth obtained by means of optimisation algorithm in the first optimisation test (related to scenario IPCC+INSTM). 


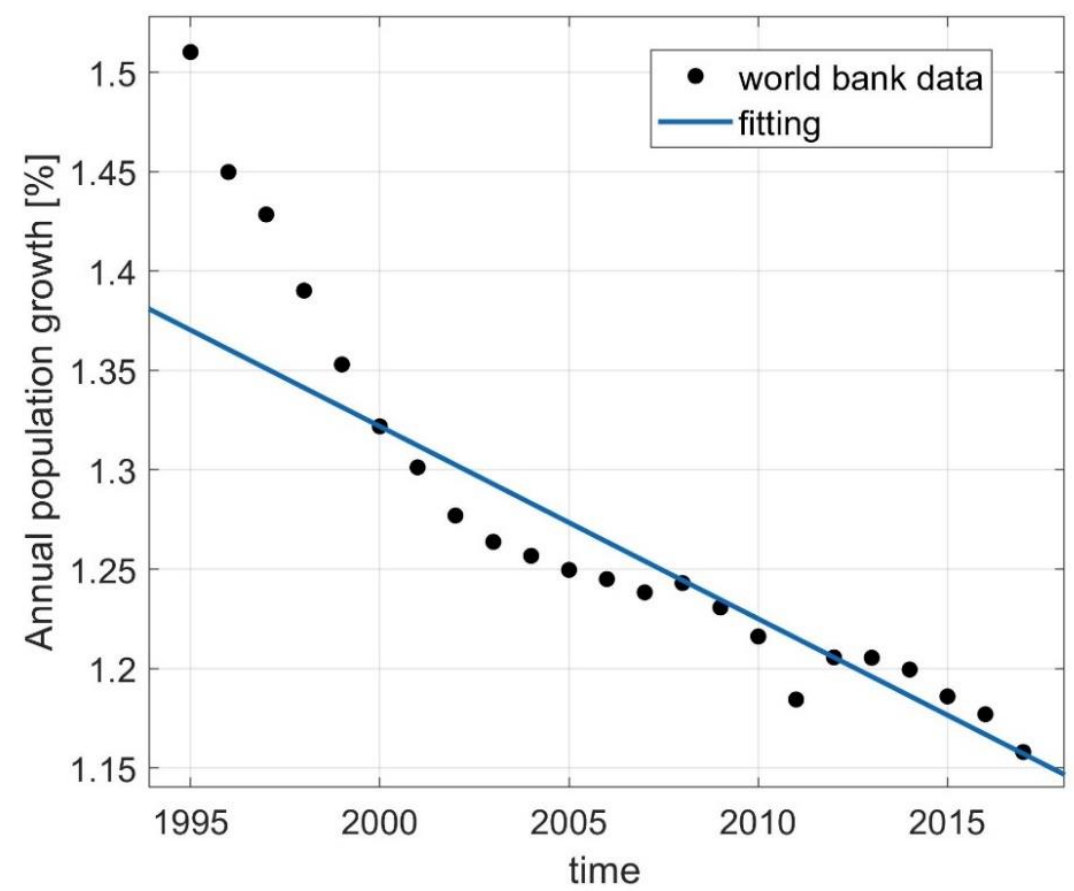

Figure 2A. Fit of the annual population growth from 1995 to 2017 (data extracted from the world bank data).

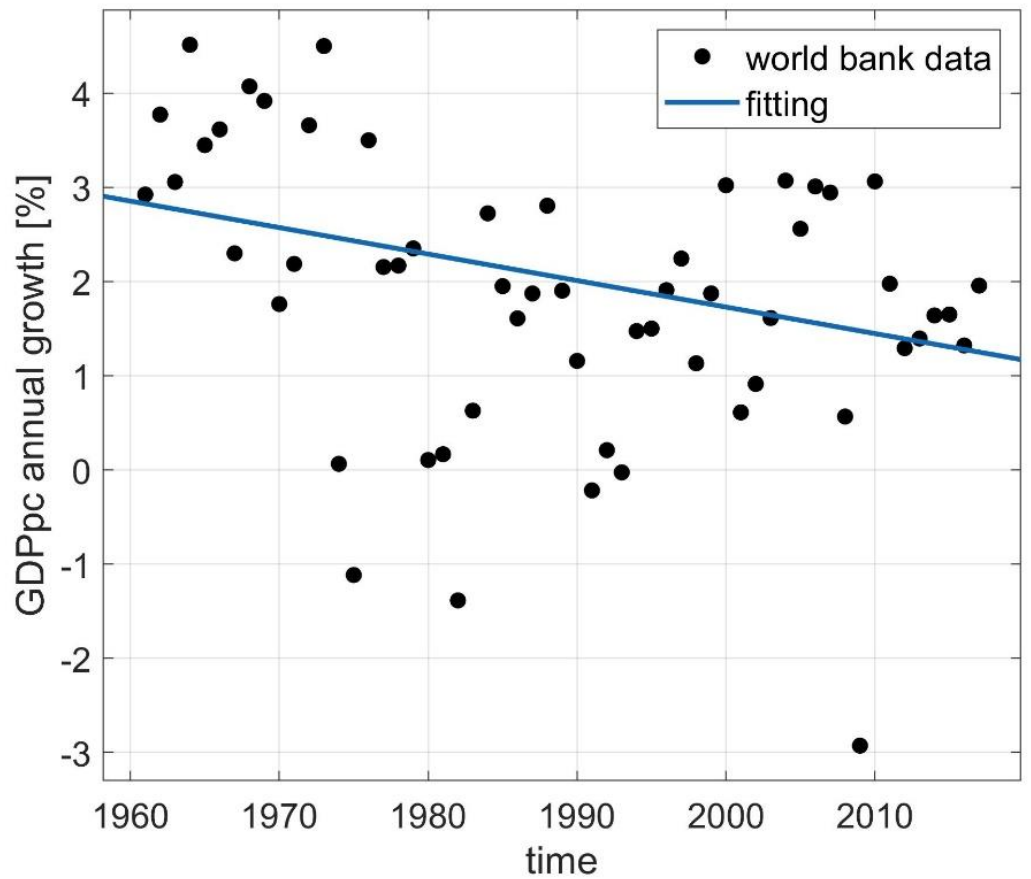

Figure 3A. Fit of the GDP pro capite annual growth from 1961 to 2017 (data extracted from the world bank data). 


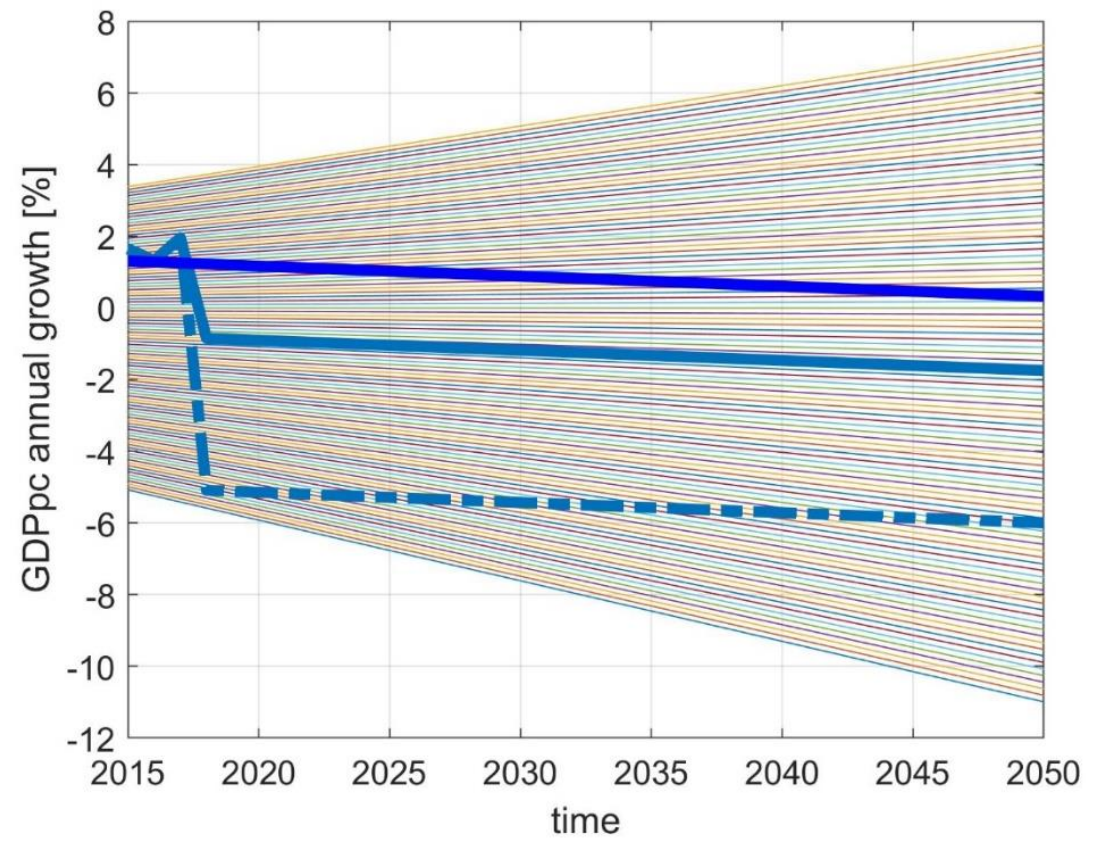

Figure 4A. Considered GDPpc variations in order to study the sensitivity analysis of the MEDEAS model (according to Figure 4.2). Also, the calibrated GDPpc annual growth and the forecast, as in Figure 3.4 , are reported.

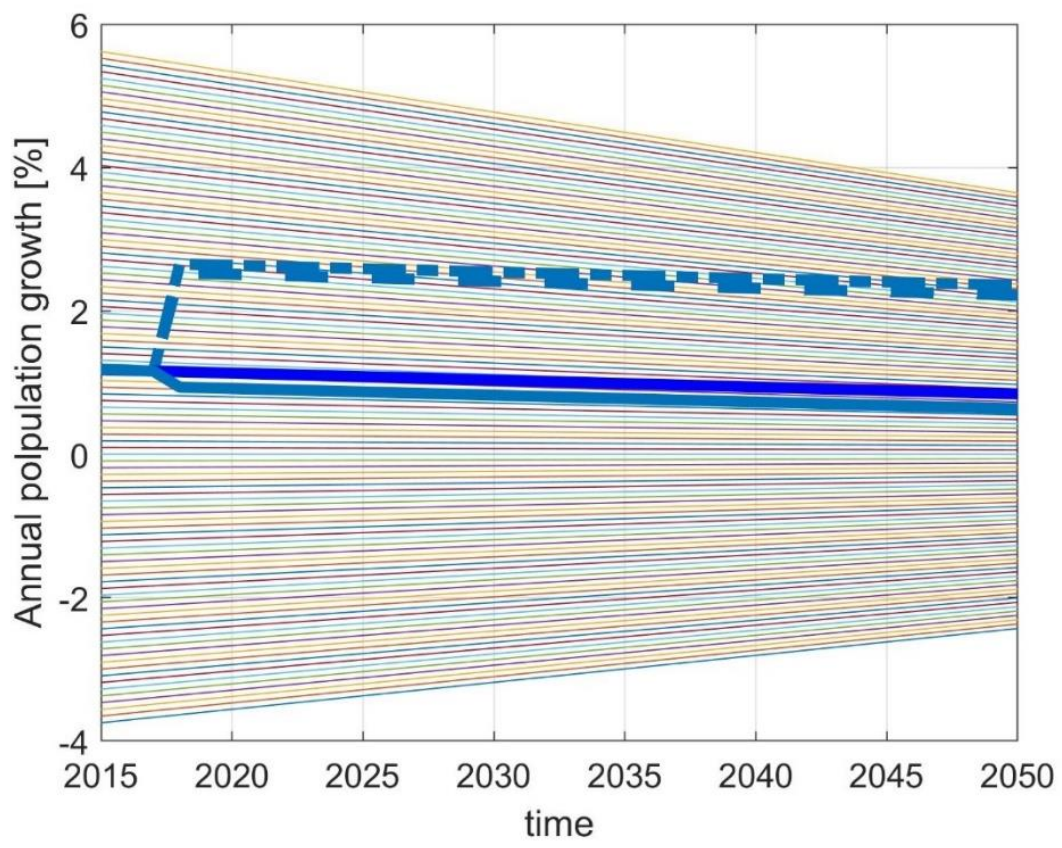

Figure 5A. Considered annual population growth variations in order to study the sensitivity analysis of the MEDEAS model (according to Figure 4.3). Also, the calibrated annual population growth and the forecast, as in Figure 3.5, are reported. 